\title{
What Is Your Reasonable Expectation of Success in Obtaining Pharmaceutical or Biotechnology Patents Having Nonobvious Claimed Inventions That the Courts Will Uphold? An Overview of Obviousness Court Decisions
}

\author{
Daniel J. Pereira and Stephen G. Kunin \\ Oblon, Spivak, McClelland, Maier \& Neustadt, LLP, Alexandria, Virginia 22314 \\ Correspondence: skunin@oblon.com
}

This article explores the legal basis for establishing the nonobviousness of patent claims in the life sciences fields of technology drawn from the guidance provided in published decisions of the U.S. Patent and Trademark Office's Patent Trial and Appeal Board, federal district courts, the Federal Circuit Court of Appeals, and the U.S. Supreme Court. Our analysis, although equally applicable to all disciplines and technologies, focuses primarily on decisions of greatest import affecting patents in the fields of pharmaceutical chemistry and biotechnology.

$\mathrm{N}$ onobviousness in patent law means that he claimed invention sought to be patented, although not identically described in the prior art, would not have been obvious to a person having ordinary skill in the art at the time the invention was made, after consideration of what was contained within the scope and content of the prior art. Determining whether a claimed invention would have been nonobvious to a person of ordinary skill in the art is a highly fact-intensive analysis, with many factors to be considered in reaching a legal conclusion as to whether the claimed invention satisfies the requirements of 35 U.S.C. $\$ 103$.

However, because of the degree of subjectivity involved in the analysis, what would have been considered to be obvious to us, may not be obvious to you and vice versa. This is the conundrum for which we struggle to find uniformity and consistency when dealing with the statutory requirement of nonobviousness that is defined in Title 35, Section 103 of the United States Code.

Editors: Salim Mamajiwalla and Rochelle Seide

Additional Perspectives on Intellectual Property in Molecular Medicine available at www.perspectivesinmedicine.org

Copyright (C) 2015 Cold Spring Harbor Laboratory Press; all rights reserved; doi: 10.1101/cshperspect.a020875

Cite this article as Cold Spring Harb Perspect Med 2015;5:a020875 


\section{OVERVIEW}

The law of nonobviousness is based on the patent statute as revised by the America Invents Act (AIA): ${ }^{1}$

35 U.S.C. \$103. Conditions for patentability; non-obvious subject matter.

(a) A patent may not be obtained though the invention is not identically disclosed or described as set forth in section 102 of this title, if the differences between the subject matter sought to be patented and the prior art are such that the subject matter as a whole would have been obvious before the effective filing date to a person having ordinary skill in the art to which said subject matter pertains. Patentability shall not be negatived by the manner in which the invention was made.

This section of the law requires that novelty of a claimed invention alone will not suffice when seeking to obtain a patent. Thus, in most cases, the primary challenge in obtaining a patent is to convince the patent examiner at the U.S. Patent and Trademark Office (USPTO) to grant the patent or, if a patent is granted, to convince a judge to confirm that the claimed invention is valid. This involves the art of persuasion that the invention set forth in the patent claims would not have been obvious to one of ordinary skill in the art as of the effective filing date of the patent application or patent.

This is the most common challenge that an applicant or patent owner faces, and often obviousness disputes are some of the most interesting (and challenging) aspects of patent law to master.

Note the importance in the law that there is a time component "at the time the invention was made" for pre-AIA applications and patents at the earliest priority date for AIA applications and patents. This is important and should never be overlooked, and as we will explore in the

\footnotetext{
${ }^{1}$ The America Invents Act became effective March 16, 2013 , for applications filed under the first-inventor-to-file provision. The only notable difference from the previous version of this section of the law is the use of "before the effective filing date" instead of "at the time the invention was made," which reflects the change in U.S. patent law from a first-toinvent system to a first-to-file system.
}

discussion that follows, the relevant time when the invention was made or at the earliest priority date can be a determinative factor as to the timing of when a claimed invention would have been obvious to a person of ordinary skill in the art. The exception to this timing provision is when the prior art qualifies under $\$ 102(b)^{2}$ as a bar to the patenting of the claimed invention. In such cases, even if the date of the invention was earlier, obviousness is judged at the time the statutory bar occurred-namely, more than 1 year before the patent applicant's earliest U.S. filing date of the pre-AIA application or earliest priority date under $\$ 102$ (b) of the AIA.

Second, the $\$ 103$ inquiry is to be done from the view of "a person having ordinary skill in the art to which said subject matter pertains." Who is this hypothetical person? The answer depends on an analysis of factors defined by the Federal Circuit through the development of the case law. Defining this person's attributes and qualifications can be important and just like the time period of inquiry can be a determinative factor as to whether the claimed invention would have been obvious. "Factors that may be considered in determining level of ordinary skill in the art include (1) the educational level of the inventor; (2) type of problems encountered in the art; (3) prior art solutions to those problems; (4) rapidity with which innovations are made; (5) sophistication of the technology; and (6) educational level of active workers in the field." 3

The Supreme Court in KSR International Co. v. Teleflex Inc. (550 U.S. 398) (2007) redefined the standard for assessing obviousness. The court determined that the Federal Circuit had been applying a rigid standard for determining whether a claimed invention would have been obvious to a person of ordinary skill in the art at the time the invention was made.

\footnotetext{
${ }^{2}$ Under pre-AIA $\$ 102(\mathrm{~b})$, a patent may not be obtained if the claimed invention was patented or described in a printed publication or was in public use or on sale for more than 1 year before the patent application's earliest U.S. filing date. ${ }^{3}$ Environmental Designs, Ltd. v. Union Oil Co. (713 F.2d 693, 696, 218 U.S.P.Q. 865, 868) (Fed. Cir. 1983), cert. denied, 464 U.S. 1043 (1984).
} 
This rigid test, known as the teaching, suggestion, or motivation test, required an express finding that the prior art provided a teaching, suggestion, or motivation as to why a claimed invention would have been obvious. The $\mathrm{Su}$ preme Court used a more flexible test based on the principles of "obvious to try," routine experimentation in which a finite number of predictable solutions to art recognized problems existed, market forces, and common sense. The consequences of this decision are that it is easier to prove obviousness for claimed inventions in the predictable technologies.

Here are some examples from the KSR decision of differences that are inconsequential and thus render a patent claim obvious: ${ }^{4}$

(a) combining prior art elements according to known methods to yield predictable results;

(b) simple substitution of one known element for another to obtain predictable results;

(c) use of known technique to improve similar devices (methods, or products) in the same way;

(d) applying a known technique to a known device (method, or product) ready for improvement to yield predictable results;

(e) "obvious to try"-choosing from a finite number of identified, predictable solutions, with a reasonable expectation of success;

(f) known work in one field of endeavor may prompt variations of it for use in either the same field or a different one based on design incentives or other market forces if the variations are predictable to one of ordinary skill in the art;

(g) some teaching, suggestion, or motivation in the prior art that would have led one of ordinary skill to modify the prior art reference or to combine prior art reference teachings to arrive at the claimed invention.

${ }^{4}$ See the USPTO's Manual of Patent Examining Procedures, $\$ 2141$.
Nonobvious Claimed Inventions in Science Fields

This analysis does have limits, however, as the Supreme Court acknowledged that:

[A] patent composed of several elements is not proved obvious merely by demonstrating that each of its elements was, independently, known in the prior art... . [I] t can be important to identify a reason that would have prompted a person having ordinary skill in the relevant field to combine the elements in the way the claimed new invention does. This is so because inventions in most, if not all, instances rely upon building blocks long since uncovered, and claimed discoveries almost of necessity will be combinations of what, in some sense, is already known. ${ }^{5}$

In the discussion that follows, we present some cases to illustrate some of the key concepts that must be kept in mind when presenting the strongest case to establish nonobviousness of claimed inventions.

\section{PATENTING DNA}

In the early 1990s, there were two cases centered on the question of obviousness of DNA claimed inventions. The first case was In re Bell (26 U.S.P.Q.2d 1529) (Fed. Cir. 1993). The claim in question was for DNA sequences encoding human insulin-like growth factor (hIGF). The prior art involved two publications disclosing amino acid sequences corresponding to specific nucleotide sequences set out in the claim. Other art taught isolating genes from a short amino acid sequence. The examiner at the USPTO concluded that the claims were obvious based on the knowledge gained from the amino acid sequences and given the fact that there are only select triplets that code for each amino acid. Bell did not like this decision, and so he filed an appeal. The appellate court (Court of Appeals for the Federal Circuit [CAFC]) disagreed with the USPTO and explained that there are approximately 1036 possible nucleotide sequences that would correspond to the amino acid sequence. Thus, the court concluded that it may be true that, knowing the structure of the protein, one can use the genetic code to hypothesize possi-

${ }^{5} I d$. at 419 . 
ble structures for the corresponding gene and that one thus has the potential for obtaining that gene. However, because of the degeneracy of the genetic code, there are a vast number of nucleotide sequences that might code for a specific protein. The USPTO had not articulated an apparent reason, based on the factual underpinnings, as to why the specific claimed invention would have been obvious.

A later case reached a similar conclusion, albeit with different facts. In Ex parte Deuel (33 U.S.P.Q.2d 1445) (B.P.A.I. 1994), the claims were directed to purified and isolated DNA sequences coding for heparin-binding growth factors. The prior art showed accurate, but partial, amino acid sequences for bovine and rat versions of the factor, including the amino-terminal portion. The art also provided a general technique for using oligonucleotide probes for isolating DNA coding for a particular protein in which the amino-terminal sequence is known. Again, the USPTO rejected the claims, concluding that the degeneracy of the genetic code did not itself preclude a finding of obviousness.

This CAFC reaffirmed its Bell decision in Deuel: "The fact that one can conceive a general process in advance for preparing an undefined compound does not mean that a claimed specific compound was precisely envisioned and therefore obvious." The CAFC did state that a different result might occur if the prior art disclosed a small and simple protein so that all DNA coding for that protein would be obvious.

Subsequent to the Supreme Court decision in KSR v. Teleflex that discussed in detail the "obvious to try" standard, the Federal Circuit decided in In re Kubin (561 F. 3d 1351) (Fed. Cir. 2009) that achieving the claimed invention would have been obvious to try. The claim at issue in that case was directed to a complementary DNA (cDNA) encoding a human cell surface protein (NAIL) expressed on natural killer cells.

The prior art showed the existence (but not sequence) of the polypeptide (p38 or NAIL), a monoclonal antibody specific for NAIL, general guidance on how to clone cDNA using monoclonal antibodies (Sambrook et al. 1989), and the cloning of a mouse homolog. The
USPTO argued that one of ordinary skill in the art would have been motivated to apply conventional methodologies to isolate and identify the cDNA sequence of human NAIL in view of the teachings of the prior art:

The problem facing those in the art was to isolate NAIL cDNA, and there were a limited number of methodologies available to do so. The skilled artisan would have had reason to try these methodologies with the reasonable expectation that at least one would be successful. Thus, isolating NAIL cDNA was the product not of innovation but of ordinary skill and common sense, leading us to conclude NAIL cDNA is not patentable as it would have been obvious to isolate it. ${ }^{6}$

Kubin argued that the prior art did not provide adequate written description of the cDNA of NAIL and relied heavily on the Deuel case as the knowledge of a protein does not render obvious the cDNA encoding it. The CAFC rejected Kubin's argument and sided with the USPTO, concluding that the claimed invention (i.e., the NAIL cDNA) is "the product not of innovation but of ordinary skill and common sense" because they "employed conventional methods, 'such as those outlined in Sambrook,' to isolate a cDNA encoding NAIL and determine the cDNA's full nucleotide sequence..." There are many ways to split hairs as to why this case decided against the DNA claim, but the main lesson is that advancements in the state of the art probably rendered that which was once unpredictable to become predictable and, therefore, obvious under an "obvious to try" standard. That is, consider the fact that the closest prior art problem for Kubin was the Sambrook lab manual published in 1989. Although both Deuel and Bell were "decided" in the early 1990s, they both related to patent applications that preceded and/or were contemporaneous with the "conventional methods" from Sambrook.

Kubin's invention of the NAIL cDNA was many years later when a new method (using an antibody to screen a library and pick out a clone) was pretty well established and there was a reasonable expectation of success in achieving the claimed invention. So it would be reason-

${ }^{6}$ Ex parte Kubin, 83 USPQ2d 1410 (BPAI 2007). 
able to presume that had Kubin discovered that cDNA a few years earlier, he may not have been denied a patent. This is why "the time the invention was made" pre-AIA or novelty-defeating activity before the priority date of the claimed invention under the AIA can be of central importance.

\section{WHO IS A PERSON HAVING ORDINARY SKILL IN THE ART?}

As was noted at the beginning of this article, the law requires that the inquiry of obviousness be viewed through the eyes of "a person having ordinary skill in the art." So that begs the question, who is this person having ordinary skill in the art?

It is a hypothetical person that does not exist but presumptively has sufficient knowledge of the prior art and how and why the knowledge of such a hypothetical person would be applied in an obviousness analysis.

Consider the case of Daiichi Sankyo Co. v. Apotex Inc. (84 U.S.P.Q.2d 1285, 1287) (Fed. Cir. 2007). The invention here was a method of creating a compound, ofloxacin, to treat ear infections, and there was litigation between the two named parties first filed in a U.S. district court that concluded that the invention was nonobvious. That conclusion was appealed to the CAFC, which reversed the district court's conclusion and found the patented invention to have been obvious. The CAFC held that the district court failed to properly define "person having ordinary skill in the art" and that when this was done, the invention was plainly obvious. That is, the CAFC reasoned that the inventors of the patent at issue exercised a higher degree of skill than just a medical degree, and so did competitors in the field. These people exhibited the skills of a seasoned researcher. As such, a person with ordinary skill in the art was more skilled than the district court's hypothetical person and, under this higher standard of a person of ordinary skill in the art, the method claimed was found to be obvious.

The conclusion makes sense if one were to consider the backgrounds of the following two individuals.
Person A is a recent college graduate with a major in biology who perhaps even has aspirations to go to graduate or medical school to hone and develop the knowledge and skills learned from undergraduate coursework and research.

Person B is a tenured professor who has years of experience in doing experiments, reviewing manuscripts for publication, reviewing grant proposals, and running a lab.

It should be apparent that a new discovery presented to person A and person B would be viewed as obvious by the more experienced person $\mathrm{B}$, given their backgrounds and experiences. This is why knowing, or rather arguing successfully, who that person of ordinary skill is and is not can be determinative on the outcome of a particular case.

\section{WHAT MAKES A CLAIMED INVENTION OBVIOUS OR NOT OBVIOUS?}

Given that the time at which the invention was made pre-AIA and before the earliest priority date of the patent under the AIA and the level of skill of the person of ordinary skill in the art are important factors in an obviousness/nonobviousness analysis, how does one ascertain if a claimed invention would have been obvious or not?

In Graham v. John Deere Co. (383 U.S. 1, 148 U.S.P.Q. 459) (1966), the U.S. Supreme Court held that the following factors should be considered when evaluating the obviousness of an invention:

1. scope and content of the prior art (i.e., what was already known in the prior art at the time the invention was made);

2. differences between the claimed invention and the prior art (i.e., why the differences between the claimed invention taken as a whole and the prior art would have been either obvious or not to one of ordinary skill in the art at the time the invention was made);

3. the level of ordinary skill in the art; 
4. "secondary considerations," which could serve as evidence for nonobviousness if they exist.

Secondary considerations may serve to tip the balance in favor of the patent holder or seeker. In the natural sciences, including biotechnology and medicine, the most often used secondary consideration is unexpected results.

In any obviousness or nonobviousness conclusion, the first step is to account for all claim limitations; that is, the claimed invention must be considered as a whole, and it is insufficient to focus only on certain aspects of the claim. In addition, the law makes it clear that prior art is not limited to what is specifically described within the document, but may include the specialized understanding of one of ordinary skill in the art as well as the common understanding of the layman. The "background knowledge possessed by a person having ordinary skill in the art can also be considered in an obviousness/nonobviousness analysis." "[A] court can take account of the inferences and creative steps that a person of ordinary skill in the art would employ." ${ }^{8}$ Thus, one may rely on, for example, official notice, common sense, and design choice.

The courts have also made reference to "predictable results" and "reasonable expectation of success." This means that in any assessment of obviousness, the outcome of the invention being assessed should have been something that one of ordinary skill would have expected at that time. Recall from the discussion of the DNA cases above that the assessment of nonobviousness changed over time, and with more information in hand, as in the Kubin case, there was a reasonable expectation of success in obtaining the coding DNA sequence even if the exact se-

\footnotetext{
${ }^{7}$ Secondary considerations, also known as objective indicia, of nonobviousness include unexpected results, commercial success, long-felt need in the art, failure of others to achieve the claimed invention, and copying by others. However, a nexus between the claimed invention and the objective indicia of nonobviousness must be proven by the patent owner. For example, see U.S. v. Adams (383 U.S. 39) (1966) and Ex parte Francis Y.F. Lee, Appeal 2007-1033, discussed further below.

${ }^{8} \mathrm{KSR}$ at 1396.
}

quence could not have been predicted, particularly in view of the advancement in the field for cloning methods.

One of the basics of obviousness is that something cannot be considered obvious if the prior art suggested going in a different direction-so-called "teaching away." The case of In re Sullivan (84 U.S.P.Q.2d 1034) (Fed. Cir. 2007) centered on an invention related to snake antivenom composed of antibody fragments, specifically, Fab fragments. It was known from prior publications that Fab fragments had been useful for detecting snake venom toxins, and there were other publications that taught the use of other types of antibody fragments as antivenoms. The USPTO found that the invention was obvious based on these facts. Yet the CAFC reached a different conclusion and found that the PTO got it wrong because it overlooked some important evidence presented by Sullivan explaining how the prior publications suggested not using Fab fragments as antivenoms.

In another set of facts, the patent application focused on a method of treating epilepsy with L-threo-methylphenidate in substantially single-enantiomer form that was initially denied patenting because it was believed to be obvious, yet this was later overturned because the very same publications believed to support the obviousness conclusion, as opposed to motivating one to use the compound in treating epilepsy, actually taught against such use. ${ }^{9}$

In Ex parte Perc, ${ }^{10}$ the claims defined pharmaceutical formulations comprising homogeneous mixtures of uncoated olanzapine or a pharmaceutically acceptable salt thereof with other pharmaceutically acceptable components. According to the USPTO examiner, the prior art disclosed the use of subcoated olanzapine in formulating pharmaceutical compositions and disclosed that uncoated olanzapine is stable when stored in polyethylene bottles. The prior art failed to disclose the use of the unpreferred uncoated olanzapine to make the formulations disclosed therein. However, the examiner relied

\footnotetext{
${ }^{9}$ Exparte Elizabeth Janina Davidson and Fiona Craig, Appeal 2007-0860.

${ }^{10}$ Appeal 2011-003119; Application 10/531,540.
} 
on the teaching of the storage stability of uncoated olanzapine and asserted that it would have been obvious to use the unpreferred uncoated olanzapine to make the prior art pharmaceutical compounds.

The USPTO Board of Appeals found that the prior art taught away from the use of uncoated olanzapine, because it disclosed that formulations having uncoated olanzapine change color over time. The prior art disclosed that patients most likely to be treated with olanzapine are patients suffering from hallucinations, where medications that change color over time would not be beneficial in treating the patient.

\section{UNEXPECTED RESULTS}

In Ex parte Francis Y.F. Lee, the court considered "unexpected results" as one of the secondary considerations in the obviousness/nonobviousness analysis. ${ }^{11}$ In this case, a cancer treatment compound was used in combination with capecitabine. It was known that the compound could be used to treat tumors and was useful in combination with other compounds for cancer treatment. It was also known to use capecitabine to treat cancer. On its face, then, it would have been obvious to combine them to treat cancer. However, there was evidence provided that the combination provided substantially improved results that were unexpected, and unexpected results override the initial presumption of obviousness.

Evidence of secondary considerations can often be found in the application as it is originally filed, but in U.S. law, we are not limited to the information contained in an application at the time of filing. Oftentimes, it is the situation where additional experiments have been conducted either in response to specific issues raised by the USPTO or because of ongoing research. That new evidence can and should, if needed, be filed in the USPTO to overcome an obviousness rejection. The form in which the data are submitted is not important, but suffice to say it is commonly done via what is called a declaration under 37 CFR 1.132 that is signed by the person or persons who did and/or supervised the experiments so that they can attest to the truthfulness of the evidence being presented. In Ex parte Treacy et al., ${ }^{12}$ the applicants had done just that - provided a wealth of data via a declaration. The USPTO Board of Appeals reversed an obviousness rejection raised by an examiner on the basis that the examiner did not properly consider unexpected results presented during examination. The invention was a synergistic insecticidal composition and a method of insect control using a synergistically effective amount of a neuronal sodium channel antagonist with one or more $\gamma$-aminobutyric acid (GABA) antagonist compounds. Because the compounds were individually known, the examiner rejected the claims as obvious on the basis of combining two known agents used for the same purpose (recall above: “(a) Combining prior art elements according to known methods to yield predictable results"). During prosecution of the patent application in the USPTO, multiple declarations were presented that demonstrated synergism on mortality rates of insect populations treated with insecticidal compositions including neuronal sodium channel antagonists and GABA antagonists. Notwithstanding this evidence, the examiner refused to allow the case based on the argument that the data were much too limited relative to the scope of the claims (this is commonly referred to as "commensurate with the scope of the claims"), a common PTO argument when an applicant uses comparative data in addressing an obviousness rejection. Specifically, the examiner's position was that " $[\mathrm{t}]$ here are over 100,000 known insect species and the combination of hundreds of compounds in formula (I) and GABA antagonists in unlimited concentrations of applications."

The board sided with the appellant because the examiner did not explain why the results were reasonably expected nor why the results lacked synergy. Regarding the examiner's con-

${ }^{11}$ Ex parte Francis Y.F. Lee, Appeal 2007-1033.

${ }^{12}$ Appeal 2011-008520; Application 11/931,434. 
tention of inadequate scope of data relative to the claims, the board opined that "[a]lthough secondary evidence must be reasonably commensurate in scope with the claims, Appellant is not required to test every embodiment that falls within the scope of the claims." The board further explained that the examiner largely ignored certain data, as the examiner only addressed an alleged deficiency in a single declaration. Further, the board, in addressing the examiner's contention of the inadequate data set particularly for untested combinations and insects, found that the examiner failed to adequately state the case: "the Examiner has not provided any rational explanation as to why the untested embodiments... would not be expected to show synergism given the scope of the data provided in the Specification and declarations."

This case is interesting on many levels. First, it gives some insight as to how unexpected results are useful to establish the patentability of an invention that otherwise at first sight (the Latin legal phrase used in these contexts is "prima facie") would be considered obvious. Second, it illustrates a common real-life situation that patent applicants face in the USPTO, i.e., the "commensurate in scope" conundrum. Third, it shows how important it can be to identify who has the burden of persuasion on a given issue; for example, in a patent application pending in the USPTO, is it the applicant or the examiner? That can be outcome determinative.

Regarding this issue of "commensurate in scope," how do you know if you have enough data and/or your claims are too broad? The answer is that it depends on (1) how close the prior art is to the invention, (2) the particular examiner that gets assigned to the case, and (3) how many variables are in play (the more variables, the more data that are likely required). To better understand this issue that is often central to obviousness, it should be useful to understand how this has developed. The rule that objective evidence of nonobviousness must be commensurate in scope with the claims was first introduced in In re Tiffin (171 U.S.P.Q. 294) (C.C.P.A. 1971). In Tiffin, the prima facie case of obviousness was rebutted by a showing of commercial success in regard to those claims limited to "cups." But where the claims were broader to cover "containers," the court held that the proof was insufficient to rebut the prima facie case. Thus, the court in Tiffin concluded that "objective evidence of nonobviousness must be commensurate in scope with the claims which the evidence is offered to support." ${ }^{\prime 3}$ In 1998, the same appellate court reaffirmed its decision and expanded the scope of the commensurate requirement to specifically encompass unexpected results. In In re Greenfield and Dupont (197 U.S.P.Q. 227) (C.C.P.A. 1978), the specification disclosed test results of the stabilizing effects of only one 3-isothiazolone (and generalized conclusions regarding a few other species) of a claimed subgenus that covers several hundred compounds. The court held that "establishing that one (or a small number of) species gives unexpected results is inadequate proof, for 'it is the view of this court that objective evidence of nonobviousness must be commensurate in scope with the claims which the evidence is offered to support.'” The Greenfield decision further relied on In re Linder (173 U.S.P.Q. 356, 358) (C.C.P.A. 1972), which held that because the claims were much broader in scope than the examples tested, there was "no adequate basis for reasonably concluding that the great number and variety of compositions included by the claims would behave in the same manner as the [single] test composition."

\section{DEFINING AND UNDERSTANDING CLAIMS IS CRITICAL IN OBVIOUSNESS DETERMINATIONS}

How an inventor defines a claim term in the application itself can control the interpretation of that term in assessing the relevant scope and content of the prior art. In Ex parte Theobald et al., ${ }^{14}$ at issue was whether in assessing the prior art's teachings and exclusions, the exam-

\footnotetext{
${ }^{13} I d$. at 294 .

${ }^{14}$ Appeal 2011-011509; Application 11/421,615.
} 
iner can ignore explicit disclaimers in the specification even if such a disclaimer is not explicitly recited in the claims.

The claims at issue were methods of using the antibacterial doxycycline to inhibit unwanted thrombin generation. The prior art of Levy was cited for its teachings of using tetracycline compounds to treat ischemia and stroke (two apparent conditions that could lead to the unwanted thrombin generation as described in Theobald's specification). The general formula of the tetracycline compounds taught by Levy was of sufficient breadth to include doxycycline and was so recited in one of the published claims (claim 42). One of the core issues of the dispute was whether the examiner could properly ignore the disclosure in Levy's specification that "expressly disclaims doxycycline from the definition of the term 'tetracycline compound," as the examiner's focus was on claim 42 , which did not include that disclaimer. The Board of Appeals of the USPTO agreed with Theobold that Levy does not suggest the use of doxycycline as a treatment because Levy had a disclaimer that operates to exclude doxycycline. ${ }^{15}$ Here the phrase "tetracycline compound" is expressly defined to exclude doxycycline, so the use of that term in claim 42 is controlled by the express definition in Levy's specification.

\section{NEW INDICATIONS FOR OLD DRUGS}

What about new uses for old products (e.g., new methods of treating a disease using a pharmaceutical in the public domain)? For example, many in the pharmaceutical field know how Viagra $^{\mathrm{TM}}$ became such a blockbuster drug despite starting off for entirely different indications. That is, the active agent in Viagra, sildenafil citrate, was initially developed by Pfizer to treat hypertension and angina pectoris, with an observed side effect, increased blood flow to the penis. This then set the course for patenting the use of sildenafil citrate for the treatment of erec-

\footnotetext{
${ }^{15}$ See Serrano v. Telular Corp. (111 F.3d 1578, 1582) (Fed. Cir. 1997). ("The inventors' definition and explanation of the meaning of the word... as evidenced by the specification, controls the interpretation of that claim term.")
}

tile dysfunction, and a new booming market was born. $^{16}$

In Jansen v. Rexall Sundown, Inc. (68 U.S.P.Q.2d 1154) (Fed. Cir. 2003), the CAFC ruled that treating a patient "in need thereof" with the goal of treating a macrocytic-megaloblastic anemia distinguished the claim from what was known previously. In particular, it is also noted that based on the treatment of an individual "in need thereof," the PTO granted claims over prior art that taught the combination of folic acid and vitamin $\mathrm{B}_{12}$ for purposes other than the claimed method. This decision followed an earlier decision in the case of Rapoport v. Dement (59 U.S.P.Q.2d 1215) (Fed. Cir. 2001), in which the CAFC was faced with a claim directed to a method for treatment of sleep apnea using an azapirone compound. The CAFC held that this new use was patentable over a reference that taught use of the same azapirone compound for the treatment of "anxiety," which was a symptom of sleep apnea. Indeed, the reference even mentioned the possibility of administering the azapirone compound to patients suffering from sleep apnea, but the CAFC noted that this was for the purpose of treating anxiety in such patients and not for the purpose of treating the sleep apnea disorder itself.

\section{OBVIOUSNESS OF PHARMA SMALL MOLECULES}

We will conclude with a discussion of obviousness of chemical compounds in the United States. Two basic principles underlie the obviousness analysis. The first is the situation in which the patent claims a chemical compound; the analysis often turns on the structural similarities and differences between the claimed compound and the prior art. The second is for the examiner to establish a prima facie case of obviousness for new chemical compounds. The examiner must identify some reason that would have led a chemist to modify a known lead compound in a particular manner to arrive at the claimed compound.

\footnotetext{
${ }^{16}$ http://www.viagrabox.com/.
} 
For example, in Takeda Chemical Industries v. Alphapharm Pty, $L t d,{ }^{17}$ the claim was to pioglitazone, a thiazolidinedione (TZD) with an ethyl-substituted pyridyl ring at the 5-position. The prior art reference described a "compound b," which differs from pioglitazone by having a methyl in place of ethyl in the 6-position instead of the 5-position. The argument for the obviousness of compound b was that it was known to be an effective antidiabetic compound, and homologation and ring-walking were within the skill of one of ordinary skill in the art such that it would have been obvious to modify compound $\mathrm{b}$ via homologation and ring-walking to produce another compound with antidiabetic activity.

The argument against obviousness, however, was based on the fact that there was no reason to choose compound b out of "hundreds of millions of TZD compounds" in the prior art. Moreover, there was a review article of 101 TZD compounds (including compound b) that suggested that compound b was not a suitable candidate for development. In addition, there was evidence in the form of comparative data that pioglitazone had unexpected levels of reduced toxicity compared to compound b.

The court found that the patent claim was valid and not obvious because (1) there was not a "finite number of identifiable, predictable solutions," because the prior art provided a broad selection of compounds with no suggestion to target compound b; and (2) the closest prior art compound exhibited negative properties.

In Ortho-McNeil Pharmaceutical, Inc. v. Mylan Laboratories, Inc. (520 F.3d 1358, 1364) (Fed. Cir. 2008), the claimed subject matter was a compound called topiramate. The argument for obviousness rested on the knowledge of a similar compound, 2,3:4,5 di-isopropylidene fructose (DPF), such that a person of ordinary skill in the art would necessarily design a fructose bisphosphate (FBPase) inhibitor ${ }^{18}$ to result

\footnotetext{
${ }^{17} 492$ F.3d 1350, 83 U.S.P.Q.2d 1169 (Fed. Cir. 2007).

${ }^{18} \mathrm{~A}$ decrease in the fluorescence polarization state of a probe provides a direct signal for binding of the inhibitor to the active site of the enzyme.
}

in topiramate. The court did not buy into this argument. The court reasoned that (1) there would have had to be some reason for a person of ordinary skill in the art to select DFP as Ortho-McNeil did (among several unpredictable alternatives); (2) the person of ordinary skill in the art would have had to identify the exact route that produced topiramate as an intermediate; (3) the person of ordinary skill in the art would have had to (at the time of invention without any clue of potential utility of topiramate) stop at that intermediate and test it for the development in the first place (epilepsy rather than diabetes); and (4) there was evidence of unexpected results (anticonvulsive activity) for topiramate.

Finally, in Eisai Co. Ltd. and Eisai, Inc., v. Dr. Reddy's Laboratories, Ltd. (533 F.3d 1353) (Fed. Cir. 2008), the claim at issue was to the drug rabeprazole. The prior art taught lansoprazole, which differs from rabeprazole by having a trifluoroethoxy substituent at the 4-position versus a methoxypropoxy substituent. The court found this patent nonobvious because there would have been no reason "to begin with lansoprazole only to drop the very feature, the fluorinated substituent that gave this advantageous property." Thus, the court followed its decision in the Takeda case, discussed above, that in determining the obviousness or nonobviousness of a particular new chemical compound "it remains necessary to identify some reason that would have led a chemist to modify a known compound in a particular manner to establish prima facie obviousness of a new claimed compound" (Takeda (492 F.3d at 1357)).

In contrast to the above cases, in Altana Pharma AG v. Teva Pharms. USA, Inc. (566 F.3d 999) (Fed. Cir. 2009), the claimed compound, pantoprazole, a proton pump inhibitor (PPI) and the active ingredient in Altana's antiulcer drug Protonix ${ }^{\circledR}$, was found to be obvious in view of the prior art. The only structural difference between the prior art compound and the claimed compound is the substituent at the 3-position of the pyridine ring, where the prior art taught a methyl group and the claimed pantoprazole had a methoxy group. There was an article that provided motivation to lower the 
Nonobvious Claimed Inventions in Science Fields

pKa of a PPI to a value of 4 to provide better stability in a patient's body. Yet another article taught that a methoxy group at the 3 -position of a pyridine ring provides a lower $\mathrm{pKa}$ than a methyl group in the same position. Further, a reference patent, the ' 518 patent, demonstrated the feasibility of substituting a methoxy group for a methyl group at the 3-position of the pyridine ring in a PPI.

Altana argued that the prior art would not have directed one of skill in the art to select the specific "lead" compound over approximately 90 compounds claimed to be improvements in the ' 518 and other prior art patents, or thousands of other compounds included in prior art disclosures. Of particular importance in this case, unlike the cases discussed above, no evidence of unexpected results was presented.

The court found the patent claim obvious, explaining that one of skill in the art would have selected the prior art compound as a lead for modification as there were articles demonstrating the benefit of substituting a methoxy group in the 3-position of the pyridine ring to achieve a $\mathrm{pKa}$ of 4 and there was no objective indicia of nonobviousness such as "unexpected results."

\section{REFERENCES}

Sambrook J, Fritsch EF, Maniatis T. 1989. Molecular cloning: A laboratory manual, 2nd ed., pp. 43-84. Cold Spring Harbor Laboratory Press, Cold Spring Harbor, NY. 


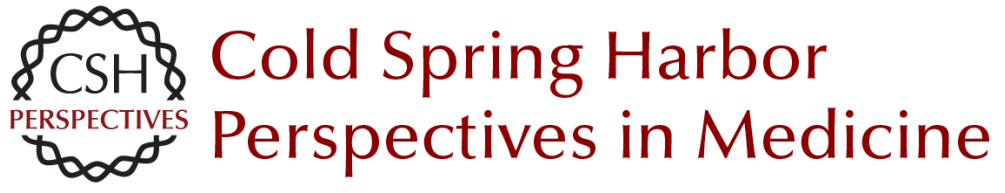

\section{What Is Your Reasonable Expectation of Success in Obtaining Pharmaceutical or Biotechnology Patents Having Nonobvious Claimed Inventions That the Courts Will Uphold? An Overview of Obviousness Court Decisions}

Daniel J. Pereira and Stephen G. Kunin

Cold Spring Harb Perspect Med 2015; doi: 10.1101/cshperspect.a020875 originally published online December 4, 2014

Subject Collection Intellectual Property in Molecular Medicine

Patentability of Stem Cells in the United States Sarah E. Fendrick and Donald L. Zuhn, Jr.

Inventorship and Authorship Antoinette F. Konski and Linda X. Wu

The Patentability of Stem Cells in Australia Jenny Petering and Prue Cowin

Impact of America Invents Act on Biotech Intellectual Property

Amanda Murphy, Michael Stramiello, Jonathan Stroud, et al.

Introduction to Intellectual Property: A U.S.

Perspective Amanda Murphy, Michael Stramiello, Stacy Lewis, et al.

The Role of Regulatory Agencies and Intellectual Property: Part I Kevin E. Noonan

Canada's Patented Medicines (Notice of Compliance) Proceedings and Intellectual Property Henry Bian and Conor McCourt

Patentability of Genes: A European Union Perspective Paul Cole
The Impact of Myriad on the Future Development and Commercialization of DNA-Based Therapies and Diagnostics

Michele Wales and Eddie Cartier

Protecting Traditional Knowledge Related to

Biological Resources: Is Scientific Research

Going to Become More Bureaucratized?

Prashant Reddy and Malathi Lakshmikumaran

Protecting Trade Secrets in Canada

Noel Courage and Janice Calzavara

Inherent Anticipation in the Pharmaceutical and

Biotechnology Industries

Michael Goldman, Georgia Evans and Andrew Zappia

The Role of Regulatory Agencies and Intellectual

Property: Part II Kevin E. Noonan

Baseball Bats and Chocolate Chip Cookies: The Judicial Treatment of DNA in the Myriad Genetics Litigation lan Binnie and Vanessa Park-Thompson

The Impact of Myriad and Mayo: Will

Advancements in the Biological Sciences Be

Spurred or Disincentivized? (Or Was Biotech

Patenting Not Complicated Enough?) Jennifer Gordon

Trade Secrets in Life Science and Pharmaceutical Companies

Tara Nealey, Ronald M. Daignault and Yu Cai

For additional articles in this collection, see http://perspectivesinmedicine.cshlp.org/cgi/collection/ 